\title{
Radiological Findings in Pulmonary Tuberculosis among HIV Infected and Uninfected Adult Patients inYenagoa, Nigeria
}

\author{
${ }^{1}$ P.O. Ikuabe, ${ }^{1}$ I.D Ebuenyi, ${ }^{2}$ Z. Ogoinja \\ ${ }^{1}$ Department of Internal Medicine, Niger Delta University Teaching Hospital, Okolobiri, Bayelsa State. Nigeria \\ ${ }^{2}$ Department of Radiology, Federal Medical Centre Yenagoa, Bayelsa State. Nigeria
}

\begin{abstract}
:
Background: Tuberculosis is one of the most serious public healthproblem globally and its pulmonary form is the most common clinical presentation. This study, undertaken in a tertiary hospital in the Niger Delta region of Nigeria, retrospectively examined the radiology features of pulmonary tuberculosis in all HIV infected and unaffected adult patients attending its pulmonary tuberculosis clinic.

Method: The chest radiography and case notes of the patients treated in the chest clinic between January 2012 and December 2013 were retrieved and evaluated according to radiological features.

Results: Of the total of 307 chest radiography studied, 156 (53.7\%) were male and 142 (46.3\%) were female, showing a male preponderance of 1.2:1. PTB/HIV co-infection was in $116(37.8 \%)$ of the cohorts studied.

The commonest radiological feature observed were cavitory lesions (63.8\%), patchy opacities (43.9\%), and hilar opacities (38.1\%). Bilateral cavitory lesions, patchy opacities and hilar opacities were commonest than on either right or left side. Bilateral chest disease was commoner in the cohorts with PTB/HIV co-infection. Perihilar patchy opacities were seen in 18.9\%, consolidation in $5.2 \%$ and pleuraleffusion in $4.6 \%$ of the cohort. Conclusion: The chest radiography, though nonspecific, still remains a sensitive tool in the diagnosis of pulmonary tuberculosis and will continue to provide essential guidance in the management and follow up of patients especially in our setting.
\end{abstract}

Keywords:Pulmonary tuberculosis, HIV, chest radiography

\section{Introduction}

In Nigeria, TB burden is compounded by a higher prevalence of HIV in the country which stands at about $3.1 \%$ in the general population. ${ }^{1,2}$ The prevalence of HIV among TB patients increased from $2.2 \%$ in 1991 to $19.1 \%$ in 2001 and $25 \%$ in 2010 . This indicates that the TB situation in the country is HIV driven.

In Africa, due to the low standard of living, famine, and inadequate shelter with associated overcrowding, the TB scourge has increased. ${ }^{3}$ The contribution of HIV infection to the resurgence of TB in sub Saharan African is now well acknowledged. ${ }^{4,5}{ }^{5}$ Most cases of TB in patient with HIV infection are probably due to reactivation of TB infection often acquired many years before. ${ }^{6}$ The most common clinical presentation of tuberculosis is the pulmonary form and it accounts for $74 \%$ of all cases. ${ }^{6,7}$

Radiography is one of the important diagnostic modalities for TB infection. ${ }^{8}$ World Health Organization (WHO) recommendations for diagnosis of PTB include - one sputum smear positive for acid fast bacilli (AFB) and radiographic abnormalities consistent with active PTB for sputum positive PTB and symptoms suggestive of PTB and three negative smear for AFB and radiographic abnormalities consistent with active PTB for sputum negative PTB. ${ }^{7}$ Smear negative patient does not exclude PTB especially when clinical symptoms and radiographic features are in support of the diagnosis. ${ }^{7,8}$

Radiography is also very valuable in the follow up of PTB patients both in the short term and long term basis.

It is also known that radiologically stable PTB lesion could still have active diseases. The objective of the study was to assess the radiological features in pulmonary tuberculosis among HIV infected and unaffected adult patients in Yenagoa, Bayelsa state, South-South Nigeria where there is a dearth of information on this subject.

\section{Materials And Methods}

The hospital ethical committee approved this retrospective study, with a waiver of informed current from the patients.

\section{Design}

A retrospective cohort analysis of all medical records of adult patients (> 15years) with pulmonary tuberculosis seen in the Federal Medical Centre, Yenagoa between January 2012 and December 2013 was undertaken using standardized data extraction form. Only cases on the TB control program with complete 
clinical details indicating diagnosis demographics, clinical and laboratory parameters especially AFB and HIV status were included. Patients who had both pulmonary and extra pulmonary tuberculosis were entered as cases of pulmonary tuberculosis and included in the study.

The diagnosis of HIV was in those patients who were reactive using two panel HIV antibody tests done in our facility with Chembio Diagnostic Systems HIV1/2 Stat Pak, USA and Uni-Gold ${ }^{\mathrm{TM}}$ HIV Trinity Biotech (NAFDAC No: 03-1011) and who were also being followed up in the HAART clinic.

\section{Setting}

The study was undertaken in the Federal Medical Centre, Yenagoa, a Tertiary Hospital in Bayelsa State, South-South, Nigeria.Yenagoa is the capital of Bayelsa in a geographical location of Lat $4^{\circ} 17^{1} \mathrm{~N}-5^{\circ} 15^{1} \mathrm{~N}$ and Longitude $6^{\circ} 15^{1} \mathrm{E}-6^{\circ} 30^{1} \mathrm{E}$ with an area of $21,1100 \mathrm{sq} \mathrm{km}$ and a population of about 1.7 million. The tuberculosis control program and HAART program are supported by the USAID and it offers comprehensive diagnosis, treatment and care of TB and HIV patients.

\section{Patient Evaluation}

All enrolled cases were managed at the TBL and HAART clinic of the Federal Medical Centre, Yenagoa. Each patient's chest radiography report was re-evaluated by a radiologist to assess the radiologic findings. All the patients were managed according to WHO recommendations.

\section{Statistical Analysis}

The results were analysed using STATA version 12 (Statacorp, College Station, Texas USA) and presented as sample percentages, graphs and charts as appropriate.

\section{Result}

The total number of chest radiograph studied were 307 of which $165(53.7 \%)$ were males and 142 $(46.3 \%)$ were female giving a male preponderance of 1.2:1 PTB/HIV infected was seen in $116(37.8 \%)$ of the cohort. Majority of the study participants were in the 31-40 years age group. Other age and sex related characteristics of the population are as shown in table 1 below.

The commonest radiography feature observed were cavitorylesions $(63.8 \%)$ patchy opacity $(43.9 \%)$ and hilar opacity $(38.1 \%)$. Bilateral cavitory lesion, patchy operatives and hilar operatives were the commonest lesion. They were more frequently seen than right sided and left sided lesions. Bilateral chest disease were commonest in both the group with PTB only and in the PTB/HIV co-infected group. Familiar patchy operation were seen in $4.6 \%$ of the cohort. Other less common features which include hilar lymphadenopathy, pneumothorax, pulmonary calcification, miliary opacities are represented in table 2 and figure 1 below.

Table 1: Age and Sex related distribution of patients with PTB/HIV Co-infection and PTB only.

\begin{tabular}{|c|c|l|l|l|l|l|c|}
\hline Age & \multirow{2}{*}{$\begin{array}{c}\text { Total no. } \\
\text { of patients }\end{array}$} & & \multicolumn{3}{|c|}{ MALES } & \multicolumn{3}{|c|}{$\begin{array}{l}\text { PTB ONLY } \\
\text { no. }(\%)\end{array}$} & $\begin{array}{l}\text { PTB/HIV } \\
\text { no. }(\%)\end{array}$ & Total no. & $\begin{array}{l}\text { PTB ONLY } \\
\text { no. }(\%)\end{array}$ & $\begin{array}{l}\text { PTB/HIV no. } \\
(\%)\end{array}$ & Total no. \\
\hline $18-20$ & 13 & $6(85.7 \%)$ & $1(14.3 \%)$ & 7 & $6(100)$ & 0 & 6 \\
\hline $21-30$ & 84 & $26(76.5 \%)$ & $8(23.5 \%)$ & 34 & $25(50 \%)$ & $25(50 \%)$ & 50 \\
\hline $31-40$ & 102 & $32(55.2 \%)$ & $26(44.8 \%)$ & 58 & $23(52.3 \%)$ & $21(47.7 \%)$ & 44 \\
\hline $41-50$ & 63 & $25(71.4 \%)$ & $10(28.6 \%)$ & 35 & $10(35.7 \%)$ & $18(64.3 \%)$ & 28 \\
\hline$\geq 51$ & 45 & $28(90.3 \%)$ & $3(9.7 \%)$ & 31 & $10(71.4 \%)$ & $4(28.6 \%)$ & 14 \\
\hline TOTAL & 307 & $117(70.9 \%)$ & $48(29.1 \%)$ & 165 & $74(52.1 \%)$ & $68(47.9 \%)$ & 142 \\
\hline
\end{tabular}

Table 2: Radiological features of patients with PTB/HIV Co-infection and PTB only.

\begin{tabular}{|c|c|c|c|c|c|c|c|c|c|c|}
\hline $\mathrm{S} /$ & \multirow[t]{2}{*}{ Radiological Features } & \multicolumn{4}{|c|}{ Patients with PTB only } & \multicolumn{4}{|c|}{ Patients with PTB/HIV Co-infection } & \multirow{2}{*}{$\begin{array}{c}\text { Grand Total } \\
(\%)\end{array}$} \\
\hline $\begin{array}{l}\mathrm{N} \\
\mathrm{o}\end{array}$ & & $\begin{array}{l}\text { Total } \\
\mathrm{N}(\%)\end{array}$ & $\begin{array}{c}\text { No. } \\
\text { With R }\end{array}$ & $\begin{array}{c}\text { No. } \\
\text { With L }\end{array}$ & $\begin{array}{c}\text { No. } \\
\text { With B }\end{array}$ & $\begin{array}{l}\text { Total } \\
\mathrm{N}(\%)\end{array}$ & $\begin{array}{c}\text { No. } \\
\text { With R }\end{array}$ & $\begin{array}{c}\text { No. } \\
\text { With L }\end{array}$ & $\begin{array}{c}\text { No. } \\
\text { With B }\end{array}$ & \\
\hline 1. & Cavitory lesions & $94(30.6)$ & 29 & 2 & 63 & $102(33.2)$ & 16 & 21 & 65 & $196(63.8 \%)$ \\
\hline 2. & Patchy opacities & $81(26.3)$ & 21 & 3 & 57 & $54(17.6)$ & 8 & 10 & 36 & $135(43.9 \%)$ \\
\hline 3. & Hilar opacities & $57(18.6)$ & 10 & 3 & 44 & $60(19.5)$ & 5 & 3 & 52 & $117(38.1 \%)$ \\
\hline 4. & $\begin{array}{l}\text { Perihilar patchy } \\
\text { opacities }\end{array}$ & $17(5.5)$ & 2 & 2 & 13 & $41(13.4)$ & 3 & 2 & 36 & $58(18.9 \%)$ \\
\hline 5. & Consolidation & $12(3.9)$ & 10 & 2 & 0 & $4(1.3)$ & 2 & 2 & 0 & $16(5.2 \%)$ \\
\hline 6. & Pleural effusion & $6(2.0)$ & 4 & 1 & 1 & $8(2.6)$ & 4 & 3 & 1 & $14(4.6 \%)$ \\
\hline 7. & $\begin{array}{l}\text { Reticulonodular } \\
\text { opacities }\end{array}$ & $5(1.6)$ & 3 & 0 & 2 & $9(3.0)$ & 4 & 1 & 4 & $14(4.6 \%)$ \\
\hline 8. & Honeycomb pattern & $9(3.0)$ & 1 & 0 & 8 & $5(1.6)$ & 1 & 3 & 1 & $14(4.6 \%)$ \\
\hline 9. & $\begin{array}{l}\text { Hilar } \\
\text { lymphadenopathy }\end{array}$ & $4(1.3)$ & 1 & 2 & 1 & $5(1.6)$ & 1 & 1 & 3 & $9(2.9 \%)$ \\
\hline
\end{tabular}


Radiological Findings in Pulmonary Tuberculosis among HIV Infected and Uninfected Adult ....

\begin{tabular}{|c|c|c|c|c|c|c|c|c|c|c|}
\hline $\begin{array}{l}1 \\
0 .\end{array}$ & $\begin{array}{l}\text { Patchy } \\
\text { reticulonodalar }\end{array}$ & $4(1.3)$ & 1 & 1 & 2 & $4(1.3)$ & 2 & 0 & 2 & $8(2.6 \%)$ \\
\hline $\begin{array}{l}1 \\
1 .\end{array}$ & $\begin{array}{l}\text { Homogenous } \\
\text { opacities }\end{array}$ & $5(1.6)$ & 3 & 2 & 0 & $2(0.7)$ & 1 & 0 & 1 & $7(2.3 \%)$ \\
\hline $\begin{array}{l}1 \\
2 .\end{array}$ & $\begin{array}{l}\text { Diffuse nodular } \\
\text { opacities }\end{array}$ & $4(1.3)$ & 3 & 0 & 1 & $3(1.0)$ & 0 & 1 & 2 & $7(2.3 \%)$ \\
\hline 3. & Pnuemothorax & $1(0.2)$ & 1 & 0 & 0 & $0(0)$ & 0 & 0 & 0 & $1(0.2 \%)$ \\
\hline $\begin{array}{l}1 \\
4 .\end{array}$ & $\begin{array}{l}\text { Pulmonary } \\
\text { calcifications }\end{array}$ & $3(1.0)$ & 1 & 0 & 2 & $0(0)$ & 0 & 0 & 0 & $3(0.7 \%)$ \\
\hline $\begin{array}{l}1 \\
5 .\end{array}$ & $\begin{array}{l}\text { Streaky patchy } \\
\text { opacities }\end{array}$ & $3(1.0)$ & 1 & 1 & 1 & $4(1.3)$ & 1 & 1 & 2 & $7(2.3 \%)$ \\
\hline $\begin{array}{l}1 \\
6 .\end{array}$ & Haziness & $4(1.3)$ & 2 & 1 & 1 & $3(1.0)$ & 1 & 1 & 1 & $7(2.3 \%)$ \\
\hline $\begin{array}{l}1 \\
7 .\end{array}$ & $\begin{array}{l}\text { Hilar \& Perihilar } \\
\text { opacities }\end{array}$ & $3(1.0)$ & 1 & 1 & 1 & $6(2.0)$ & 1 & 2 & 3 & $9(2.9 \%)$ \\
\hline $\begin{array}{l}1 \\
8 .\end{array}$ & Streaky opacities & $4(1.3)$ & 1 & 1 & 2 & $1(0.2)$ & 0 & 0 & 1 & $5(1.6 \%)$ \\
\hline $\begin{array}{l}1 \\
9 .\end{array}$ & Widespread opacities & $6(2.0)$ & 2 & 1 & 3 & $5(1.6)$ & 1 & 2 & 3 & $11(3.5 \%)$ \\
\hline $\begin{array}{l}2 \\
0 .\end{array}$ & Miliary opacities & $3(1.0)$ & 0 & 0 & 3 & $1(0.2)$ & 0 & 0 & 1 & $4(1.3 \%)$ \\
\hline
\end{tabular}

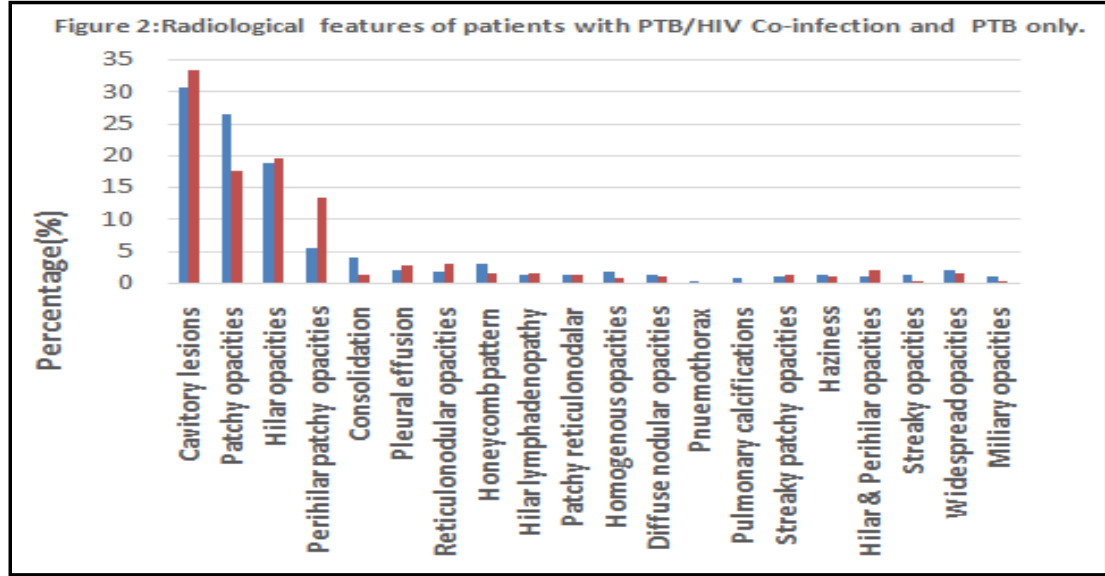

\section{Discussion}

It is well acknowledged that chest radiography is a sensitive but nonspecific test to detect tuberculosis. ${ }^{10}$ However, radiographic examination of the thorax may be useful to identify persons for further evaluation. This is even more so if such persons have negative sputumsmears to attempt to find evidence for pulmonary tuberculosis and to identify other abnormalities that may be responsible for the symptoms. With regard to tuberculosis, radiographic examination is most useful when applied as part of a systemic approach in the evaluation of persons whose symptoms and/or findings suggest tuberculosis, but who have negative sputum smears.

In this study, a male preponderance of PTB was observed and is consistent with findings of previous studies. ${ }^{11,12,13,14}$

A female preponderance was, however, observed in an earlier report from South-West Nigeria. ${ }^{15}$ Other socio-economic factorsmay explain this phenomenon as some other studies have shown. ${ }^{15,16}$

In sub Saharan Africa, the tuberculosis case rate continues to increase, both because of the epidemic of HIV infection and the poor or absent primary care services in parts of our region. ${ }^{7}$ This is shown in our study where the prevalence of $\mathrm{PTB} / \mathrm{HIV}$ co-infected is $37.8 \%$. A number of other studies have reported high prevalence rate of PTB/HIV co-infected and noted that HIV effectors can be complicated by PTB. ${ }^{4,13,14}$ All these studies pointed to the usefulness of chest radiography in the management of especially the smear negative PTB.

The chest radiographic features of PTB are well known. They include the usual, characteristic upper zone infiltrates, cavitory lesion and hilar or Perihilar opacities. ${ }^{17,18}$ We found these features most commonly in this study. The formation of cavities with surrounding infiltrative changes in adult patient isthe main radiographic finding in PTB generally. ${ }^{12,14,15}$ This is what we found too in the study.

These cavities were more often bilateral as well as the opacities, thus, suggesting involvement of more than one lobe as was reported by some workers. ${ }^{4,5}$ In patients with HIV and those with pulmonary tuberculosis, it was noted that radiographic findings were more subtle and may show low-zone infiltrate or miliary pattern. ${ }^{10,18}$ 
In our study, where cavities occurred on only one side, it was more common on the right side, especially in the cohort with PTB only. This is similar to the findings in earlier reports. ${ }^{10,18}$ The persons with PTB/HIV co-infection presented with more frequency of cavitory lessons than those with only PTB. This does not agreed with the report from China which reported that individuals co-infected with PTB and HIV where less likely to have cavitory lessons than those with only $\mathrm{PTB}^{.4} \mathrm{We}$ recorded pleural effusion in only $4.6 \%$ of our cases.

Reliance on chest radiograph as the only diagnostic test for tuberculosis will result in both overdiagnosisof tuberculosis and missed diagnosis of tuberculosisand other diseases. This is a well acknowledged fact. However, it continues to provide essential confirmation for the management and follow-up especially as regards complication. ${ }^{17}$

\section{Limitation}

The limitations we identified in our study include the fact that only PA films were evaluated. We might thus, have missed out on minimal effusions mediastinal or tiny hilar lymph nodes. Secondly, some patients may not have been able to do chest radiograph because of financial reasons as the donor agency did not avail patients of this facility free of charge.

\section{Conclusion}

Even in resource poor settings, chest radiograph should be done whenever it is affordable by persons with pulmonary tuberculosis in addition to the sputum specimen submission for microbiological examination.

\section{Competing Interest}

Authors have declared that no competing interest exist.

This work was carried out in collaboration between all authors. Authors POI did the study design and wrote the protocol. Authors IDE did the statistical analysis and literature searches while analysis of study was by author ZO. All authors read and approved the final manuscript.

\section{References}

[1]. World Health Organization (WHO).Global report: UNAIDS report on the global AIDS epidemic 2013. UNAIDS / JC2502/1/E"Revised and reissued, November 2013(accessed on $25^{\text {th }}$ October, 2014).

[2]. Center for Disease Control (CDC) TB and HIV infection; January tuberculosis fact sheet. http://cdc.gov/tuberculosis (accessed on 25th of July 2014).

[3]. Tuberculosis Division of the International Union against Tuberculosis and Lung Diseases. Tuberculosis bacteriology. Priorities and indications in high prevalence countries; position of the technical staff of the tuberculosis division of the International Union against Tuberculosis and Lung disease. Int. J Tubere Lung Dis. 2005; 9:355-361.

[4]. Lu Px, Yu Wy, Zhu Wk et al. Radiological features of AIDS complicated by pulmonary tuberculosis and the association with CD4 T lymphocytes. ZhonguaJieHeHe Hu Xi ZaZhi 2005; 28: 13-6

[5]. BusiRizzi E, SchininaV, Palmieri F, Girardi E, Bibbolino C, cavitary pulmonary tuberculosis HIV related. Eur J Radiol 2004; 52: $170-4$.

[6]. ElzingaG, Raviglime MC, Maher D. scale-up: Meeting targets in global tuberculosis control lancet 2004; $363: 814$.

[7]. World Health Organization. Global tuberculosis control. Surveillance, planning, financing. In WHO report2005. Geneva. World Health Organization; 2005: 1-258.

[8]. National Tuberculosis and leprosy control programme (NTBLCP) workers manual 2004. Federal Ministry of Health. Nigeria.

[9]. Meintjes G, Lawn SD, Scano F, Tuberculosis-associated Immune reconstitution inflammatory syndrome. Case definitions for use in resource - limited settings. The Lancet infectious diseases; 2008; 8 (8); 516-523.

[10]. Koppaka R, Bock N, how reliable is chest radiography? In:FriedenTR,ed. Toman's Tuberculosis. Case detection, treatment and monitoring. $2^{\text {nd }}$ edition. Geneva: World Health Organization 2004. 51-60.

[11]. Ismail V, Pulmonary tuberculosis - a review of clinical features and diagnosis in 232 cases. Med J Malaysia 2004; 59: 56-64.

[12]. Szczuka I. Tuberculosis in Poland in 2003. PrzeglEpidemiol 2005; 59: 353-61.

[13]. Uneka CJ, Alo MN. Rising cases of smear - positive pulmonary tuberculosis in south-eastern Nigeria: The public health implication. Afr J. Respir Med. 2006; 1:11-14.

[14]. Nivonwu EU, Oyibo PG, Imo AOC, Ndukwe CD. Et al. Radiological features of pulmonary tuberculosis in HIV - positive and HIV-negative adult patients in south-eastern Nigeria Afr J Respir Med. 2008, 20-23.

[15]. Erinle SA. An appraisal of the radiological feature of pulmonary tuberculosis in Ilorin. Nig. Postgrad Med J. 2003; 10:264-9.

[16]. Ikuabe PO, Sawyer WE. Impact of Scarcity of automobile fact on attendance at a referred centre for tuberculosis in Nigeria NJM. 2005; 14:51-54.

[17]. Andrew J, Caceres J, Pallisa E, Martinez Rodriguez M. Radiological Manifestation of pulmonary tuberculosis. Eur. J Radiol. 2004; 57:139-49.

[18]. Ikuabe, PO, Jumbo J, Ebuenyi ID, Ogoinja Z. Lower lung field tuberculosis: observations from Yenagoa, Nigeria IJTDH. 2015; 5 (1):25-29 